\title{
A PROPOSITO DE LA HISTORIA \\ DE CATALUÑA EN LOS SIGLOS XVI-XVII
}

\author{
CARLOS MARTINEZ SHAW \\ Universidad de Barcelona
}

Me siento en la obligación de expresar públicamente mi profunda discrepancia con la recensión que sobre el libro de Ricardo García Cárcel (Historia de Cataluña, siglos XVI-XVII) firma Gaspar Feliu en esta misma RevisTa DE Historia Económica que hoy acepta mi réplica y a la que agradezco su acogida. Me he decidido a romper mi costumbre de no interferirme en los juicios críticos ajenos a causa de la manifiesta hostilidad que desprende la citada reseña y que parece desplazar animadversiones personales al terreno de la obra científica y a causa de la inadmisible descalificación final que condena inquisitorialmente y sin atenuantes un trabajo de investigación serio en su planteamiento y dilatado en su realización.

No quiero entrar en esta breve nota en todas aquellas opiniones manifestadas por Gaspar Feliu y que corresponden al ámbito de lo discutible, como son sus afirmaciones sobre «el desorden que preside tanto el esquema general como la confección de los distintos apartados», sobre «el extraño reparto de los hechos económicos entre los tres niveles de la obra" o sobre otras cuestiones de este mismo nivel, ya que en eso reside el legítimo ejercicio de la crítica historiográfica.

Solamente quiero poner en evidencia la saña que denotan muchas de sus objeciones puntuales a supuestos errores, perseguidos con lupa y con laborioso esfuerzo digno de mejor causa a lo largo de las páginas del libro. Así, el lugar común de los contemporáneos sobre la longevidad de los habitantes de la Cerdaña (que se dice viven ordinariamente ochenta o noventa años) es atribuido al autor, como si después de sus anteriores estudios de demografía histórica pudiese en rapto de enajenación temporal sostener afirmaciones de este tenor. Del mismo modo, descalifica la dedicación oleícola del Urgell tomada sin más de la tesis doctoral (t. II, p. 241) de una de las máximas especialistas del tema, Montserrat Durán. Tampoco pueden pasarse por alto sus lecturas abusivas de las observaciones del autor sobre el papel de la masía como eje de la actividad rural catalana (una generalización que se matiza convenientemente en otros varios pasajes de la obra), sobre la diferente incidencia 
de la Sentencia de Guadalupe, según los distintos grupos en que se articulaba la nobleza, o sobre la compatibilidad entre una transmisión hereditaria contraria a la fragmentación de la propiedad agraria y el funcionamiento paralelo de toda otra serie de mecanismos de transferencia de tierras. El lenguaje alcanza en cualquier caso sus mayores tonos insultantes cuando se encarniza en la detección de las que sarcásticamente denomina «perlas» de la exposición: en un caso, la alteración de unas palabras por la imprenta priva de sentido a la aseveración del autor sobre la disposición de las casas, que está literalmente tomada de la excelente contribución de Albert García Espuche y Manuel Guàrdia Bassols al I Congrés d'Història Moderna de Catalunya (t. I, p. 684). De idéntico modo, el error de darle dignidad episcopal a Pau Claris (en una ocasión, frente a otras en que aparece correctamente caracterizado como canónigo) no podía ser más que un desliz cuando el autor del libro lo es al mismo tiempo de la mejor biografía de Pau Claris que puede encontrarse, y que después de obtener el premio "Joan Estelrich» ha conocido ya dos ediciones (Dopesa y Ariel).

Sin embargo, nada de lo señalado me hubiera impelido a redactar esta nota si no hubiese sido por el ataque final negando el pan y la sal a este libro, incapaz, según se nos advierte, de contribuir «a un mejor conocimiento de la historia de Cataluña». Como ya expuse en otra ocasión (recensión en La Vanguardia, 6 marzo 1986), la obra de Ricardo García Cárcel cubre un vacío en la historiografía catalana (el vacío de los dos segles d'obscuritat de la época de los Austrias), mediante la aportación de una gran cantidad de materiales inéditos (fruto de investigaciones propias o de investigaciones ajenas realizadas bajo su dirección en la Universidad Autónoma de Barcelona), mediante la atrevida desmitificación de tradiciones interpretativas obsoletas (sobre el régimen foral, la contribución catalana a la Hacienda real, la actitud oficial frente a la Inquisición o el neoforalismo de fines del xvir, entre otros temas de semejante trascendencia), mediante el planteamiento valiente de problemas viciados por una intoxicación menos historiográfica que política (abarcando nada menos que el acercamiento a la «realidad nacional» de Cataluña desde una óptica histórica, el cuestionamiento del presunto «carácter específico catalán» o la reformulación del sentido de las relaciones entre Cataluña y la Monarquía española), mediante su propósito, sin duda elogiable (y nada apriorístico en cuanto es una intención y no presupone la validez del resultado, pese al sofisma empleado por Gaspar Feliu) de contribuir a través de la Historia a una mejor comprensión entre los ciudadanos que habitan este país.

Por su esfuerzo documental (que no se libra de acusaciones, en este caso por el exceso en ofrecer testimonios contemporáneos), su valentía para afrontar los problemas realmente importantes en un contexto difícil y su posición 
ética en favor de la convivencia y la tolerancia, el libro hubiera merecido un crítico con más capacidad para apreciar sus aciertos y menos acritud para acechar sus carencias. Afortunadamente para Ricardo García Cárcel y para su obra, no ha sido el único, y otras personas más autorizadas que Gaspar Feliu y que yo, y mejores conocedoras de la época, como, por ejemplo, don Antonio Domínguez Ortiz, se han pronưnciado de modo muy diferente. 